Check for updates

Cite this: RSC Adv., 2017, 7, 29159

Received 21st March 2017

Accepted 18th May 2017

DOI: 10.1039/c7ra03334f

rsc.li/rsc-advances

\section{Enhancing the water repellency of wood surfaces by atmospheric pressure cold plasma deposition of fluorocarbon film}

\author{
Pedro Henrique Gonzalez de Cademartori, (D) ${ }^{a}$ Luc Stafford, $^{\mathrm{b}}$ Pierre Blanchet, (D) \\ Washington Luiz Esteves Magalhães (D) and Graciela Ines Bolzon de Muniz (D) *a
}

In this study, fluorocarbon thin films were deposited on the surface of white spruce and Brazilian cedar woods via atmospheric pressure dielectric barrier discharge in the afterglow mode with octafluoropropane gas. A pretreatment with oxygen plasma was introduced before the thin film deposition to determine if this plasma condition could increase the wood nano/micro roughness, helping to improve the hydrophobicity of the surface. The optimal conditions of water repellency for both woods were examined in terms of their resistance to aging in controlled conditions. The water contact angle measurements showed a hydrophobic surface with a stable angle for both woods. $\mathrm{X}$-ray photoelectron spectroscopy reveals the presence of $\mathrm{CF}$, $\mathrm{CF}_{2}$ and $\mathrm{CF}_{3}$ functional groups after the $\mathrm{Ar} / \mathrm{C}_{3} \mathrm{~F}_{8}$ plasma, especially for longer treatments. The open-air system of the plasma reactor leads to the simultaneous fluorination and incorporation of oxygen-containing groups. The pre-treatment of oxygen plasma increases the wood roughness; however, the chemical attachment of oxygen molecules is more significant, negatively affecting the degree of repellency of the plasma-coated woods. On the other hand, the fluorocarbon deposition increases the wood roughness and creates a hydrophobic surface simultaneously. Even with partial defluorination after aging, both plasma-coated woods retain a similar degree of water repellency, which partially avoid chemical reorganization of their surface due to environmental exposure.

\section{Introduction}

Wood is a sustainable and renewable material but its hygroscopic surface can limit its use for several applications, and thus requires repellency against polar and non-polar liquids. Expanding the functionalization of wood surfaces is receiving great interest to produce new materials with better properties, especially using methods based on materials science such as nanotechnology. Many techniques have been applied to change the wetting properties of the wood surface, most of which involve wet chemistry, such as hydrothermal processes, ${ }^{1}$ sol-gel processes $^{2}$ and spraying of nanoparticles. ${ }^{3}$

Among the techniques for surface modification, plasma treatment is extensively used to change the surface of this material. It is

${ }^{a}$ Programa de Pós-Graduação em Engenharia Florestal, Universidade Federal do Paraná, 632 Lothário Meissner Avenue, 80210-170, Curitiba, Paraná, Brazil. E-mail: pedrocademartori@gmail.com; gbmunize@ufpr.br; Tel: +55-41-3360-5328; +55-41-88445311

${ }^{b}$ Département de Physique, Université de Montréal, H3C 3J7, Montréal, Québec, Canada.E-mail: luc.stafford@umontreal.ca

${ }^{c}$ NSERC Industrial Research Chair on Ecoresponsible Wood Construction, Wood and Forest Department, Laval University, G1V0A6, Quebec City, Quebec, Canada. E-mail: pierre.blanchet@sbf.ulaval.ca

${ }^{d}$ Embrapa Florestas, Centro Nacional de Pesquisa de Florestas, 83411-000, Colombo, Paraná, Brazil. E-mail: washington.magalhaes@embrapa.br more interesting than the usual wet techniques because it is a dry and a clean process with little environmental impact. In certain cases, traditional chemical treatments are often expensive and can result in the leaching of toxic substances. ${ }^{4}$ Some characteristics of plasma treatment are often impossible to reproduce using common chemical methods. For example, specific components in the plasma discharge present a higher energy density than that by common chemical methods and plasma has a high concentration of charged chemical species, such as ions, electrons and metastables, which help to reduce the activation energy for chemical reactions. ${ }^{5,6}$ Moreover, plasma treatment can be used to change the surface roughness of materials by etching and introducing reactive groups on their surface without any modification of their bulk properties. ${ }^{7,8}$ Etching and chemical changes by the introduction of reactive groups on the surface and surface cleaning and crosslinking of near-surface molecules are considered the four major effects during plasma discharge which can act individually or in synergistically. ${ }^{9}$ These major effects drive the application of plasma treatments for different goals, such as antifouling properties, ${ }^{\mathbf{1 0}}$ biocompatibility, ${ }^{11}$ superhydrophobicity, ${ }^{12}$ improving surface adhesion, ${ }^{13,14}$ oxygen barrier properties ${ }^{15}$ and antibacterial properties. ${ }^{16}$

The application of plasma in wood and wood-based materials involves two main goals, the improvement of surface adhesion ${ }^{17-21}$ and the deposition of low surface energy thin films to increase the barrier properties against polar and non-polar 
liquids and gases. The deposition of low surface energy films on the wood surface is relatively well understood in low-pressure plasma reactors from the many reports published, which mainly use siloxanes, fluorine and alkanes as precursors. ${ }^{\mathbf{8 2 2 - 2 6}}$

On the other hand, in the last two decades there has been growing interest in thin film deposition via atmospheric pressure cold plasma technologies; ${ }^{27}$ however, unlike other natural and synthetic materials, this field of study has not been fully explored for wood and wood-based materials, especially using fluorine precursors. The few studies published in the literature focused on functionalization with hexamethyldisiloxane (HMDSO), ${ }^{28-30} \mathrm{ZnO}-$ $\mathrm{SiO}_{2}$ coatings ${ }^{31}$ and other precursors, such as ethane, methane, ethylene, chlorotrifluoroethylene and hexafluoropropylene. ${ }^{32,33}$ At the same time, the importance of atmospheric pressure plasma technology is highlighted by the fact that is an interesting alternative for use in the wood industry due to both the generation of cold plasma, which means plasma discharge generated at room temperature, in open systems ${ }^{34}$ and the easy implementation in a continuous production line. ${ }^{35}$

The intrinsic characteristics of wood lead to strong aging effects mainly through the wood inactivation phenomenon. This phenomenon can induce changes in the chemical properties of the wood surface, thus reducing the plasma effect on the wood surface with time. Additionally, the plasma-wood interactions are complex because the plasma source produces active species that can provide a large number of chemical and physical changes in the main constituents presented in the wood surface, including cellulose, lignin, hemicelluloses and extractives. ${ }^{36}$ Depending on the plasma conditions applied and the initial conditions of the substrate, the surface energy of the wood increases or decreases.

In the case of dielectric barrier discharges (DBD), Levasseur et $a .^{28}$ confirmed that the treatment of wood and textiles is a challenge compared to other conventional materials since the plasma deposition dynamics not only depends on the chemical structure of these polymers but also on their porous microstructure and the presence of impurities on their surface. As a matter of fact, wood surface treatment by inert or reactive gases is controversial since both hydrophobic and hydrophilic characteristics have been reported using the same precursor. For example, as expected, previous studies observed the hydrophilization of the wood surface by oxygen $\left(\mathrm{O}_{2}\right)$ treatment, in some cases followed by an increase in roughness. ${ }^{37-39}$ On the other hand, Prégent et al. ${ }^{36}$ reported recently the hydrophobization of a wood surface treated by $\mathrm{N}_{2} / \mathrm{O}_{2}$ plasma in an afterglow system at atmospheric pressure due to the increase of neutral gas at a temperature of $75^{\circ} \mathrm{C}$, which led to similar conditions to wood heat treatment at temperatures lower than $150{ }^{\circ} \mathrm{C}$. Levasseur et al. ${ }^{28}$ observed the time dependence of DBD treatment because short periods led to the deposition of an $\mathrm{SiO}_{x}$ hydrophilic layer, whereas longer times (>10 min) resulted in a hydrophobic layer containing $\mathrm{Si}\left(\mathrm{CH}_{3}\right)_{3}-\mathrm{O}-\mathrm{Si}\left(\mathrm{CH}_{3}\right)_{2}, \mathrm{Si}\left(\mathrm{CH}_{3}\right)_{3}$, and $\mathrm{Si}\left(\mathrm{CH}_{3}\right)_{2}$ functional groups.

In this context, this study investigates the deposition of fluorocarbon thin films with octafluoropropane $\left(\mathrm{C}_{3} \mathrm{~F}_{8}\right)$ on the surface of white spruce and Brazilian cedar woods via DBD afterglow plasma by simulating an industrial line and focusing on the optimal conditions for high water repellency. Moreover, a pre-treatment of $\mathrm{O}_{2}$ plasma is introduced to understand if the physical and/or chemical changes imposed by $\mathrm{O}_{2}$ plasma before thin film deposition can improve the hydrophobicity of the wood-coated surface. The optimal conditions are evaluated towards the resistance of plasma treated wood against aging in controlled conditions.

\section{Material and methods}

\section{Wood samples preparation}

White spruce (Picea glauca (Moench)) and Brazilian Cedar (Erisma uncinatum Warm.) woods were used as raw materials. The original boards were cut into small wood samples measuring $12.5 \times 12.5 \times$ $2 \mathrm{~mm}$ (length $\times$ width $\times$ thickness) in the tangential direction. Before the plasma treatments, the wood samples were stored under vacuum $\left(10^{-6}\right.$ torr $)$ overnight to remove the outgassed gases and volatile organic compounds. Then, they were sanded with 180grit sandpaper and cleaned with a compressed air flow to remove surface sawdust.

\section{DBD afterglow plasma treatments}

Plasma treatments were performed in a planar DBD ATMOS reactor (Plasmionique, Canada) equipped with a conveyer system which simulates an industrial line. This device operates at atmospheric pressure with a variable alternating current generator connected to an amplifier for ignition and sustention of the discharge. The discharge was open between two metallic electrodes with area of $285 \mathrm{~cm}^{2}$ covered by quartz plates separated by a distance of $0.14 \mathrm{~mm}$ and the samples were placed in the flowing afterglow of the DBD. More details can be obtained in the report by Prégent et al. ${ }^{36}$

The plasma treatments were conducted at $6 \mathrm{kHz}$ under different conditions (Table 1) using argon (Ar) as the carrier gas for both $\mathrm{O}_{2}$ and $\mathrm{C}_{3} \mathrm{~F}_{8}$ plasma discharges. The gases were mixed before entering the discharge zone and their flow was controlled by a mass flow system. The distance between the wood samples and the DBD outlet was set at $3 \mathrm{~mm}^{\mathbf{4 0}}$ and the speed of the conveyer was set at $0.5 \mathrm{~cm} \mathrm{~s}^{-1}$. The low speed increased the plasma exposure time of the wood samples for each pass in the conveyer. The time of treatment was estimated according to the number of passes in the plasma afterglow discharge. One pass corresponds to approximately $0.33 \mathrm{~s}$.

The plasma discharge characteristics (current-voltage, $I-V$ ) were measured using a high-voltage probe (Tektronix P6015A, USA) and recorded with an oscilloscope (Tektronix TDS 2012B, USA). The measurements were performed three times: in the first few seconds, in the middle and in the final discharge.

\section{Contact angle measurements}

The wettability of the untreated and plasma treated samples was measured with an Attention goniometer (Biolin Scientific, Sweden) using the sessile drop method at room temperature. The measurements were performed before and after plasma treatments on each sample, assuming the natural heterogeneity of the wood surface. Three deionized water (surface tension of $72.80 \mathrm{mN} \mathrm{m}^{-1}$ ) droplets with a $5 \mu \mathrm{L}$ volume were dispensed on 
Table 1 Operation parameters for the $\mathrm{O}_{2}$ and the $\mathrm{C}_{3} \mathrm{~F}_{8}$ DBD afterglow plasma treatments

\begin{tabular}{lll}
\hline & \multicolumn{2}{c}{ DBD treatment } \\
\cline { 2 - 3 } Parameters & $\mathrm{Ar} / \mathrm{O}_{2}$ & $\mathrm{Ar} / \mathrm{C}_{3} \mathrm{~F}_{8}$ \\
\hline $\begin{array}{l}\text { Flow rate }- \text { precursor } \\
\text { gas (sccm) }\end{array}$ & 20 & 5 \\
$\begin{array}{l}\text { Peak-to-peak applied } \\
\text { voltage (kV) }\end{array}$ & $12-14$ & $10-11$ \\
$\begin{array}{l}\text { Number of passes } \\
\text { (time of treatment) }\end{array}$ & $20(\sim 6.6 \mathrm{~s})$ and & $20(\sim 6.6 \mathrm{~s})$, \\
& $60(\sim 19,8 \mathrm{~s})$ & $100(\sim 33 \mathrm{~s})$ and \\
$\begin{array}{l}\text { Argon flow } \\
\text { (carrier gas, in sccm })^{a}\end{array}$ & 30 & $400(\sim 66 \mathrm{~s})$ \\
$\begin{array}{l}{ }^{a} \text { High argon flow rates were used to guarantee that the active species } \\
\text { reached the wood surface. }\end{array}$
\end{tabular}

the surface of each wood sample. The water contact angle (WCA), the droplet volume and the baseline were recorded for $10 \mathrm{~s}$ on the tangential wood face and in the perpendicular direction to the fibers. Measurements with the non-polar solvent diiodomethane were also performed to determine the surface free energy based on the Wu theory (eqn (1)). ${ }^{\mathbf{4 1 , 4 2}}$

$$
\gamma_{1 \mathrm{~s}}=\sigma_{1}+\sigma_{\mathrm{s}}-4\left(\frac{\sigma_{1}^{\mathrm{D}} \times \sigma_{\mathrm{s}}^{\mathrm{D}}}{\sigma_{1}^{\mathrm{D}}+\sigma_{\mathrm{s}}^{\mathrm{D}}}+\frac{\sigma_{1}^{\mathrm{P}} \times \sigma_{\mathrm{s}}^{\mathrm{P}}}{\sigma_{1}^{\mathrm{P}}+\sigma_{\mathrm{s}}^{\mathrm{P}}}\right)
$$

where, $\sigma_{1}=$ surface tension of the liquid; $\sigma_{\mathrm{s}}=$ surface tension of the solid phase; $\gamma_{1 \mathrm{~s}}=$ interfacial tension between the liquid and the solid phases; $\mathrm{D}=$ dispersion component and $\mathrm{P}=$ polar component.

The WCA measurements were performed after 40 days of exposure in controlled conditions (temperature of $20{ }^{\circ} \mathrm{C}$ and $65 \%$ relative humidity) to evaluate the aging effect on the untreated and plasma treated wood surfaces. All the collected data were analyzed by descriptive statistics.

\section{Profilometer measurements}

The surface roughness of the untreated and plasma treated samples were analyzed with a non-contact 3D Contour GT-K1 profilometer from Bruker (USA). Measurements were performed in the VSI mode using a $5 \times$ objective lens and a green laser. The parameters Spk (reduced peak height), Sk (core roughness depth) and Svk (reduced valley depth) were determined in triplicate for each wood sample. The cut-off used to analyze the roughness parameters was $0.025 \mathrm{~mm}$ and the Gaussian regression filter was applied for the subsequent data collection. The collected data were analyzed by the analysis of variance (ANOVA) at 5\% probability of error. When the null hypothesis was rejected $(p<0.05)$, the average values were compared using the Tukey HSD (honestly significant difference) test at $5 \%$ probability of error.

\section{XPS analysis}

The elemental and chemical composition of the surface of the untreated and plasma treated wood samples were determined via X-ray photoelectron spectroscopy (Axis-Ultra, Kratos UK). General survey and high-resolution spectra (C 1s, O 1s and F 1s)
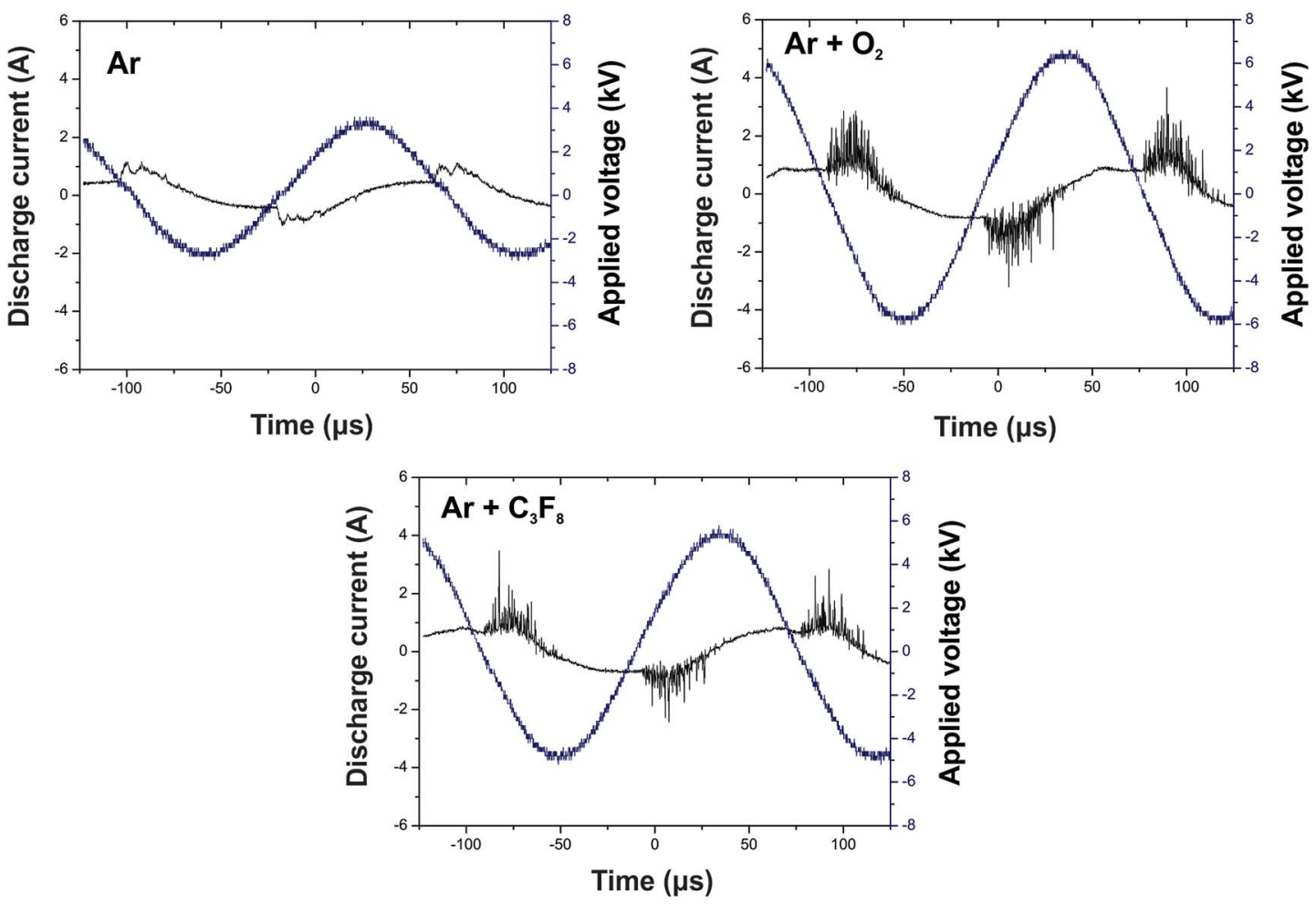

Fig. 1 Current-voltage characteristics of the DBD in $\mathrm{Ar}, \mathrm{Ar}+\mathrm{O}_{2}$ and $\mathrm{Ar}+\mathrm{C}_{3} \mathrm{~F}_{8}$. 
were recorded using a monochromatic $\mathrm{Al} \mathrm{K} \alpha \mathrm{X}$-ray source at $300 \mathrm{~W}$ with a neutralizer to avoid the electrostatic charge effect. Calculation of the apparent relative atomic concentrations and peak fitting were performed with the CasaXPS software assuming that the analyzed spot (approximately $800 \mu \mathrm{m} \times 400$ $\mu \mathrm{m} \times 5 \mathrm{~nm}$ ) was homogeneous.

\section{Results and discussion}

The current-voltage waveforms of the DBD afterglow plasma in $\mathrm{Ar}, \mathrm{Ar} / \mathrm{O}_{2}$ and $\mathrm{Ar} / \mathrm{C}_{3} \mathrm{~F}_{8}$ are given in Fig. 1. The discharge current for all DBD plasma treatments operates in the filamentary mode, which is characterized by multiple peaks with a duration of nanoseconds. The density and the amplitude of the spikes generated by the microdischarges can characterize the quality of the glow obtained. ${ }^{43}$ The number of microdischarges increased after the addition of both reactive $\mathrm{O}_{2}$ and fluoropolymer gases with large molecular weight, which disturbed the regime and caused a shift to a highly filamentary mode.

The untreated wood samples for both species display hydrophilic behavior. The hydrophilicity of the untreated samples is most pronounced for white spruce wood (Fig. 2). After $2 \mathrm{~s}$ of droplet deposition, the WCA decreases to $\sim 50 \%$ and $\sim 28 \%$ for the white spruce and Brazilian cedar woods, respectively. During $10 \mathrm{~s}$ of measurement, both spreading and absorption phenomena can be seen in the untreated samples due to the decrease in the volume and baseline of the droplets (Table 2).

The $\mathrm{Ar} / \mathrm{C}_{3} \mathrm{~F}_{8}$ treatments in the DBD afterglow at atmospheric pressure increased the hydrophobicity of the woods surfaces, especially in the white spruce. The WCA showed "sticky" droplets on the surface, which indicates the absence of superhydrophobicity. The water repellency increased with an increase in the number of passes (i.e. time of treatment) under the plasma discharges. After 20 passes $(=\sim 6 \mathrm{~s})$, the WCA of the white spruce wood increased from $90^{\circ}$ to $117.4^{\circ}$, whereas the WCA of the Brazilian cedar wood increases in lower proportion (from $91.6^{\circ}$ to $109^{\circ}$ ). The use of 100 passes $(\sim 33 \mathrm{~s}$ ) also resulted in a significant increment in the hydrophobicity for both woods, especially for the white spruce. However, the best results were found after 200 passes ( $66 \mathrm{~s}$ ), which suggests that the DBD afterglow polymerized fluorocarbon film has sufficient
Table 2 Averages values of the volume and baseline* of the water droplets after $1 \mathrm{~s}$ and $10 \mathrm{~s}$ of droplet deposition for the woods nontreated and treated by $\mathrm{Ar} / \mathrm{C}_{3} \mathrm{~F}_{8} \mathrm{DBD}$ afterglow plasma ${ }^{a}$

\begin{tabular}{llllll}
\hline & \multicolumn{2}{c}{ Volume $(\mu \mathrm{L})$} & & \multicolumn{2}{l}{ Baseline $(\mathrm{mm})$} \\
\cline { 2 - 3 } Treatment & $1 \mathrm{~s}$ & $10 \mathrm{~s}$ & & $1 \mathrm{~s}$ & $10 \mathrm{~s}$ \\
\hline WS untreated & $2.15(0.48)$ & $0.81(0.39)$ & & $2.00(0.26)$ & $2.50(0.44)$ \\
WS 20 passes & $2.80(0.29)$ & $1.71(0.39)$ & & $1.65(0.10)$ & $1.79(0.25)$ \\
WS 100 passes & $3.16(0.24)$ & $2.80(0.41)$ & & $1.46(0.21)$ & $1.53(0.29)$ \\
WS 200 passes & $2.94(0.29)$ & $2.85(0.33)$ & $1.36(0.16)$ & $1.35(0.17)$ \\
BC untreated & $2.29(0.39)$ & $1.55(0.41)$ & $2.02(0.26)$ & $2.41(0.38)$ \\
BC 20 passes & $3.00(0.21)$ & $2.29(0.27)$ & $1.87(0.14)$ & $2.35(0.32)$ \\
BC 100 passes & $2.94(0.23)$ & $2.37(0.39)$ & $1.68(0.13)$ & $1.92(0.33)$ \\
BC 200 passes & $2.91(0.30)$ & $2.78(0.40)$ & & $1.47(0.16)$ & $1.56(0.28)$
\end{tabular}

${ }^{a} \mathrm{WS}=$ white spruce wood and $\mathrm{BC}=$ Brazilian cedar wood. ${ }^{*}$ Baseline means the border between the droplet shape and the surface of the sample.

fluorination. The WCA of the white spruce wood increased to $135.20^{\circ}$, whereas that of the Brazilian cedar reached $129.83^{\circ}$. This degree of fluorination significantly changed the surface free energy (SFE) of the woods. Based on the $\mathrm{Wu}$ calculation, the SFE decreased from $58 \pm 4 \mathrm{mN} \mathrm{m}^{-1}$ to $21 \pm 5 \mathrm{mN} \mathrm{m}^{-1}$ in the white spruce and from $53 \pm 2 \mathrm{mN} \mathrm{m}^{-1}$ to $18 \pm 5 \mathrm{mN} \mathrm{m}^{-1}$ in the Brazilian cedar after the $\mathrm{Ar} / \mathrm{C}_{3} \mathrm{~F}_{8}$ treatment with 200 passes. As expected, both the dispersive and polar parts decreased after the fluorination, where the latter reached close to zero for both the white spruce and Brazilian cedar woods.

The most pronounced characteristic for the longer treatments with $\mathrm{Ar} / \mathrm{C}_{3} \mathrm{~F}_{8}$ was the stable WCA. With an increase in the number of passes, the WCA remained practically stable for the white spruce wood without significant changes in both volume and baseline characteristics (Table 2). The same characteristic was observed for the Brazilian cedar to a lesser degree. Besides the fluorination on the surface, the better behavior of the white spruce could be related to the wood surface roughness, which will be discussed later. The difference in the WCA stabilization between 20, 100 and 200 passes may be related to the insufficient deposition of fluorocarbon-containing groups, which results in a higher affinity between wood surface and liquid water. According to a previous report, ${ }^{\mathbf{4 4}}$ for post-discharge
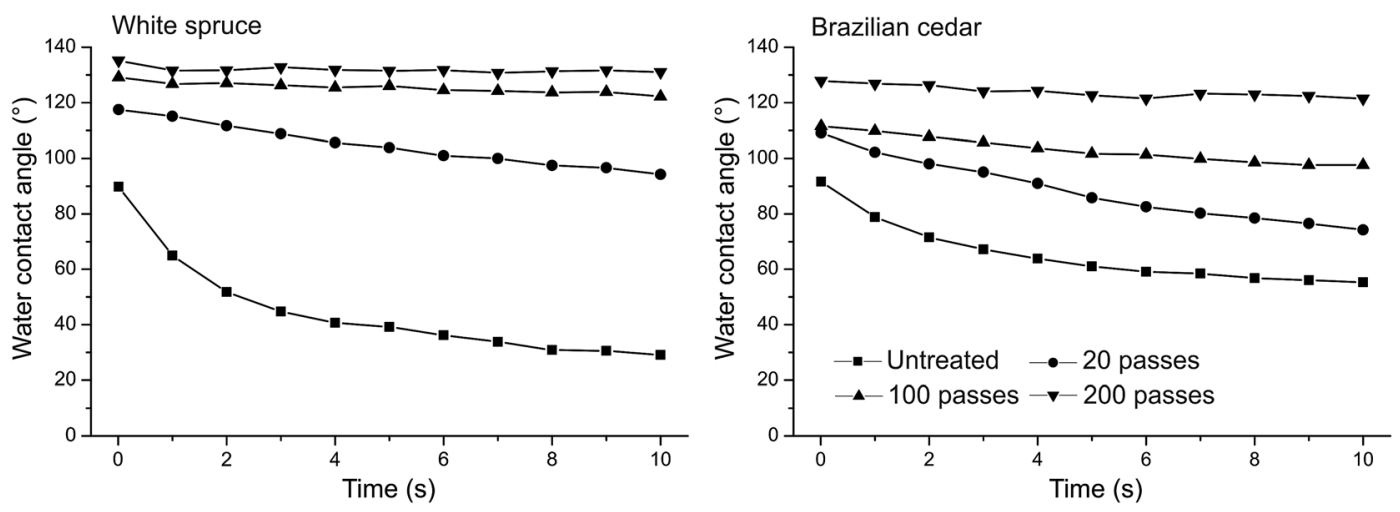

Fig. 2 Time-resolved WCA for the woods non-treated and treated by $A r / C_{3} F_{8}$ DBD afterglow plasma. 
Table 3 Atomic concentration and atomic ratio obtained by XPS for the woods treated by $\mathrm{Ar} / \mathrm{C}_{3} \mathrm{~F}_{8} \mathrm{DBD}$ afterglow plasma

\begin{tabular}{|c|c|c|c|c|c|c|c|}
\hline Wood species & Passes- $\mathrm{Ar} / \mathrm{C}_{3} \mathrm{~F}_{8}$ & \multicolumn{4}{|c|}{ Atomic concentration (\%) } & \multicolumn{2}{|c|}{ Atomic ratio } \\
\hline & 100 & 68.97 & 7.56 & 22.12 & 1.36 & 0.109 & 0.320 \\
\hline & 200 & 69.22 & 9.46 & 20.01 & 1.31 & 0.136 & 0.289 \\
\hline Brazilian cedar & Untreated & 77.06 & - & 19.37 & 3.38 & - & 0.251 \\
\hline
\end{tabular}

${ }^{a}$ Many atoms in no significant percentage were considered as contaminants: $\mathrm{Ca}, \mathrm{Cl}, \mathrm{Si}, \mathrm{Al}, \mathrm{N}$ and $\mathrm{S}$.
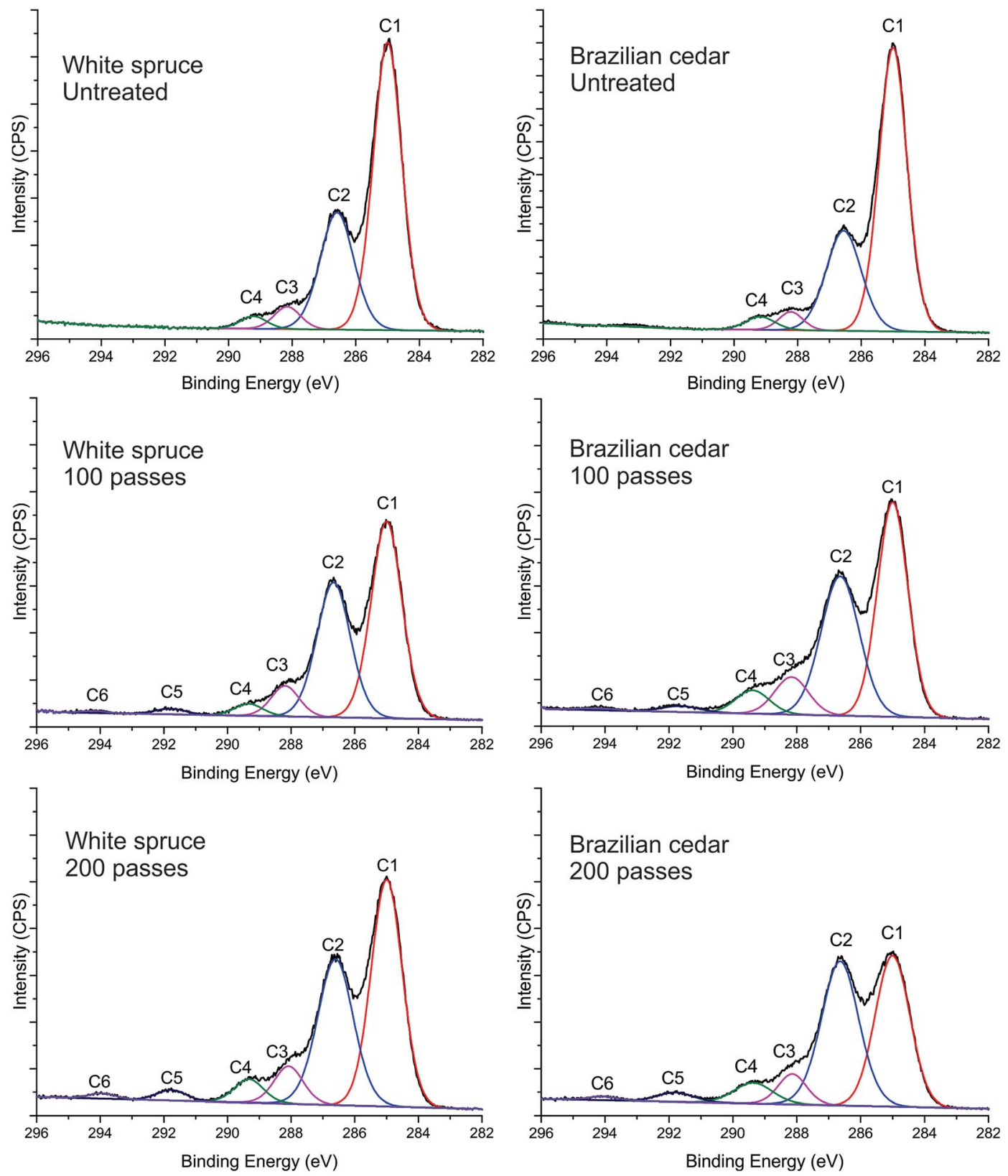

Fig. 3 High-resolution $C$ 1s spectra of the woods before and after the $A r / C_{3} F_{8}$ DBD afterglow plasma treatments. 
configurations, the low concentration of active species that reaches the surface results in lower deposition rates. Moreover, the presence of oxygen-containing groups due to the open-air system in the afterglow plasma reactor and the lower quantity of positive ions and metastable atoms and molecules ${ }^{45}$ could reduce the fluorocarbon deposition, as can be seen for 20 passes. The same unstable contact angle was observed by Liu et al. (2009) in plasma-coated paper with fluorocarbon films at atmospheric pressure.

The XPS analysis shows that the untreated wood samples are composed mainly of oxygen (19-20\%) and carbon (77-79\%) with varying percentages according to the wood species (Table 3). Some traces of contamination were detected mainly because the plasma discharges were performed at atmospheric pressure in an open system. The concentration of carbon decreased, whereas the concentration of oxygen increased after the $A r / C_{3} F_{8}$ deposition at atmospheric pressure, regardless of the wood species and the number of passes used in the plasma treatment. The $\mathrm{F} / \mathrm{C}$ and $\mathrm{O} / \mathrm{C}$ ratios increased after the $\mathrm{Ar} / \mathrm{C}_{3} \mathrm{~F}_{8}$ plasma treatments for both 100 and 200 passes, which indicates fluorination and the incorporation of oxygen-containing groups at the same time, where the latter is due to the treatment at atmospheric pressure.

Fitting of the high-resolution C 1s spectra was performed to obtain better insight into the chemical changes resulting from the DBD afterglow plasma treatments (Fig. 3).
The C 1s spectra of the untreated samples of white spruce and Brazilian cedar wood were decomposed into four main peaks, $\mathrm{C} 1(\mathrm{C}-\mathrm{C}$ and $\mathrm{C}-\mathrm{H})$ at $285.0 \mathrm{eV}, \mathrm{C} 2(\mathrm{C}-\mathrm{O})$ at $286.59 \mathrm{eV}, \mathrm{C} 3$ $\left(\mathrm{C}=\mathrm{O}, \mathrm{O}-\mathrm{C}-\mathrm{O}\right.$ and $\left.\mathrm{C}-\mathrm{CF}_{n}\right)$ at $288.15 \mathrm{eV}$ and $\mathrm{C} 4(\mathrm{O}=\mathrm{C}-\mathrm{O}$ and $-\mathrm{CF})$ at $289.22 \mathrm{eV}$. The fluorination with $\mathrm{C}_{3} \mathrm{~F}_{8}$ for both 100 and 200 passes resulted in the addition of new functional groups to the wood surface, where a decrease in $\mathrm{C}-\mathrm{C} / \mathrm{C}-\mathrm{H}$ groups and increase in oxygen-containing groups, especially ester (C2 peak) and carbonyl (C3 peak) groups were observed. This increase in C2 and C3 peaks is mainly attributed to the interaction of oxygen molecules during the plasma discharge since the treatments were performed at atmospheric pressure. The appearance of CF groups in the $\mathrm{C} 1 \mathrm{~s}$ spectrum can be observed through two main peaks, $\mathrm{C} 5\left(-\mathrm{CF}_{2}\right)$ at $291.8 \mathrm{eV}$ and $\mathrm{C} 6\left(-\mathrm{CF}_{3}\right)$ at $294.2 \mathrm{eV}$. Furthermore, the addition of $\mathrm{CF}$ groups can be observed on a lesser scale by the $\mathrm{C}-\mathrm{CF}_{n}$ and $-\mathrm{CF}$ groups at 288.15 and $289.22 \mathrm{eV}$. A higher percentage of $\mathrm{CF}_{2} / \mathrm{CF}_{3}$ results in higher hydrophobicity and higher water contact angles of the materials. ${ }^{46}$ Also, it should be highlighted that the $\mathrm{C} 5$ peak attributed to $-\mathrm{CF}_{2}$ groups is higher than $\mathrm{C} 6$ peak $\left(-\mathrm{CF}_{3}\right)$. This higher proportion can be seen for the treatment with 100 passes and it increases with an increase in the treatment time (200 passes). This is in accord with the hydrophobic characteristic of the plasma-treated wood surfaces, including their high and stable WCA, as seen previously for the treatment with 200 passes in Fig. 2. Furthermore, the high-resolution F 1s spectra (Fig. 4) for
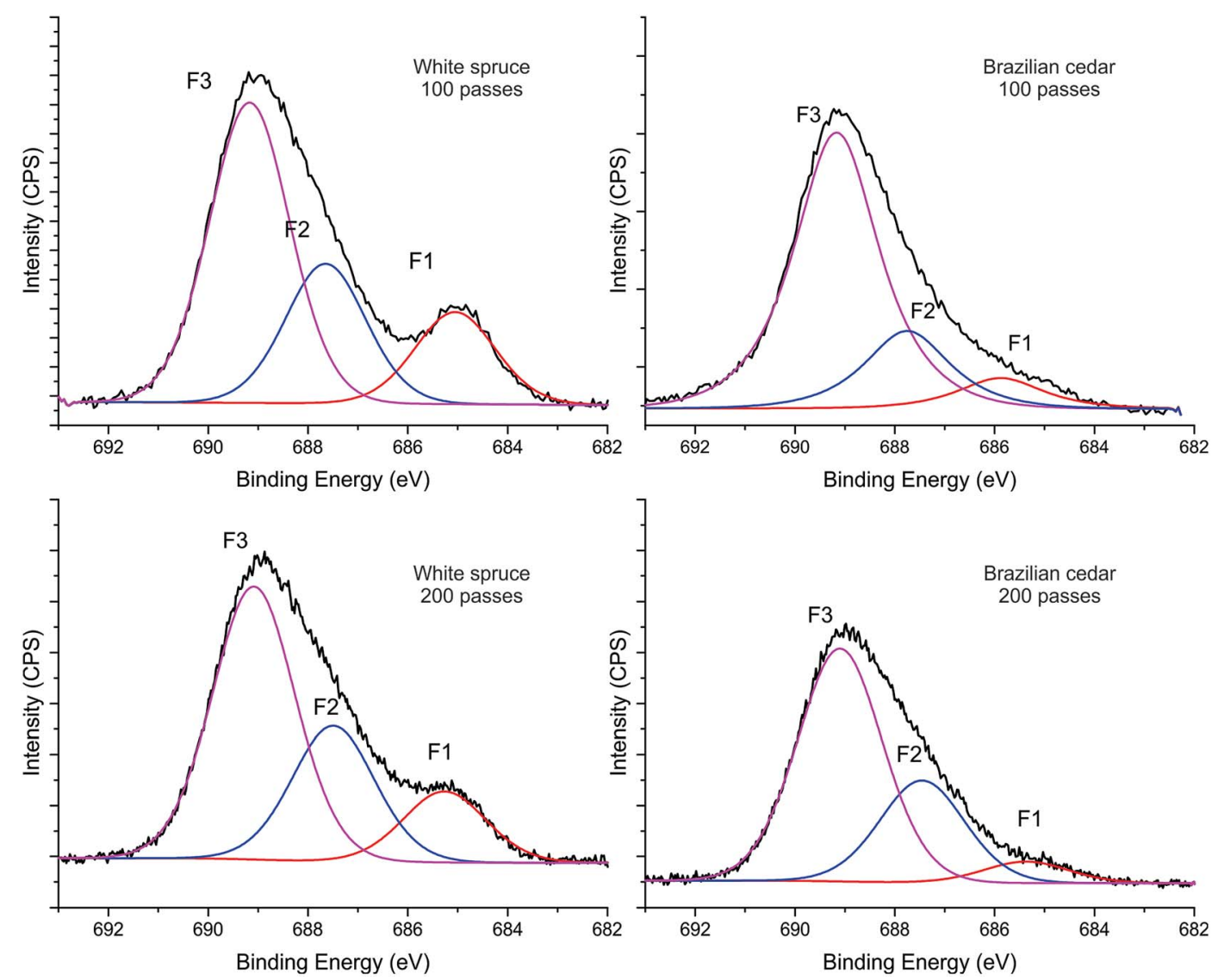

Fig. 4 High-resolution $\mathrm{F}$ 1s spectra of the woods before and after the $\mathrm{Ar} / \mathrm{C}_{3} \mathrm{~F}_{8} \mathrm{DBD}$ afterglow plasma treatments. 
both wood species show the presence of fluorinated groups at $685.2 \mathrm{eV}, 687.7 \mathrm{eV}$ and $689.2 \mathrm{eV}$, which may represent various C$\mathrm{F}, \mathrm{CF}_{2}$ and $\mathrm{CF}_{3}$ bonds with or without $\mathrm{O}$.

Both the surface energy and the surface roughness of a material are important parameters that affect its degree of wettability. ${ }^{47}$ Previous studies showed that the positive effect of $\mathrm{O}_{2}$ plasma increases the nano/micro roughness of materials, ${ }^{\mathbf{4 8 , 4 9}}$ which helps to generate a hydrophobic or superhydrophobic surface with the subsequent deposition of a low surface energy film. .2,50,51 $^{\text {There- }}$ fore, this study demonstrates the effect of a pre-treatment with $\mathrm{O}_{2}$ plasma in a DBD afterglow system to improve the wood surface roughness by etching and tries to create a more hydrophobic surface with the subsequent fluorocarbon deposition.
Nevertheless, the addition of a pre-treatment of $\mathrm{O}_{2}$ plasma before the $\mathrm{Ar} / \mathrm{C}_{3} \mathrm{~F}_{8}$ deposition resulted in a negative effect on the water repellency of the wood-coated surfaces (Fig. 5A and B), regardless of the treatment time applied. The WCA of the white spruce and Brazilian cedar coated-woods decreased with the addition of $\mathrm{O}_{2}$ plasma pre-treatment, both with 20 passes $(\sim 6,6$ s) and 60 passes $(\sim 19,8 \mathrm{~s})$. Besides the decrease in initial WCA, the $\mathrm{O}_{2}$ pre-treatment affected the stabilization of the samples. $\mathrm{An}_{2}$ pre-treatment with 20 passes was enough to eliminate the WCA stabilization reached with 100 passes and mainly 200 passes of $\mathrm{Ar} / \mathrm{C}_{3} \mathrm{~F}_{8}$, which is very similar to the results obtained for the coating with 20 passes of $\mathrm{Ar} / \mathrm{C}_{3} \mathrm{~F}_{8}$, as displayed in Fig. 2. A larger number of passes in the $\mathrm{O}_{2}$ pre-treatment (60 passes)
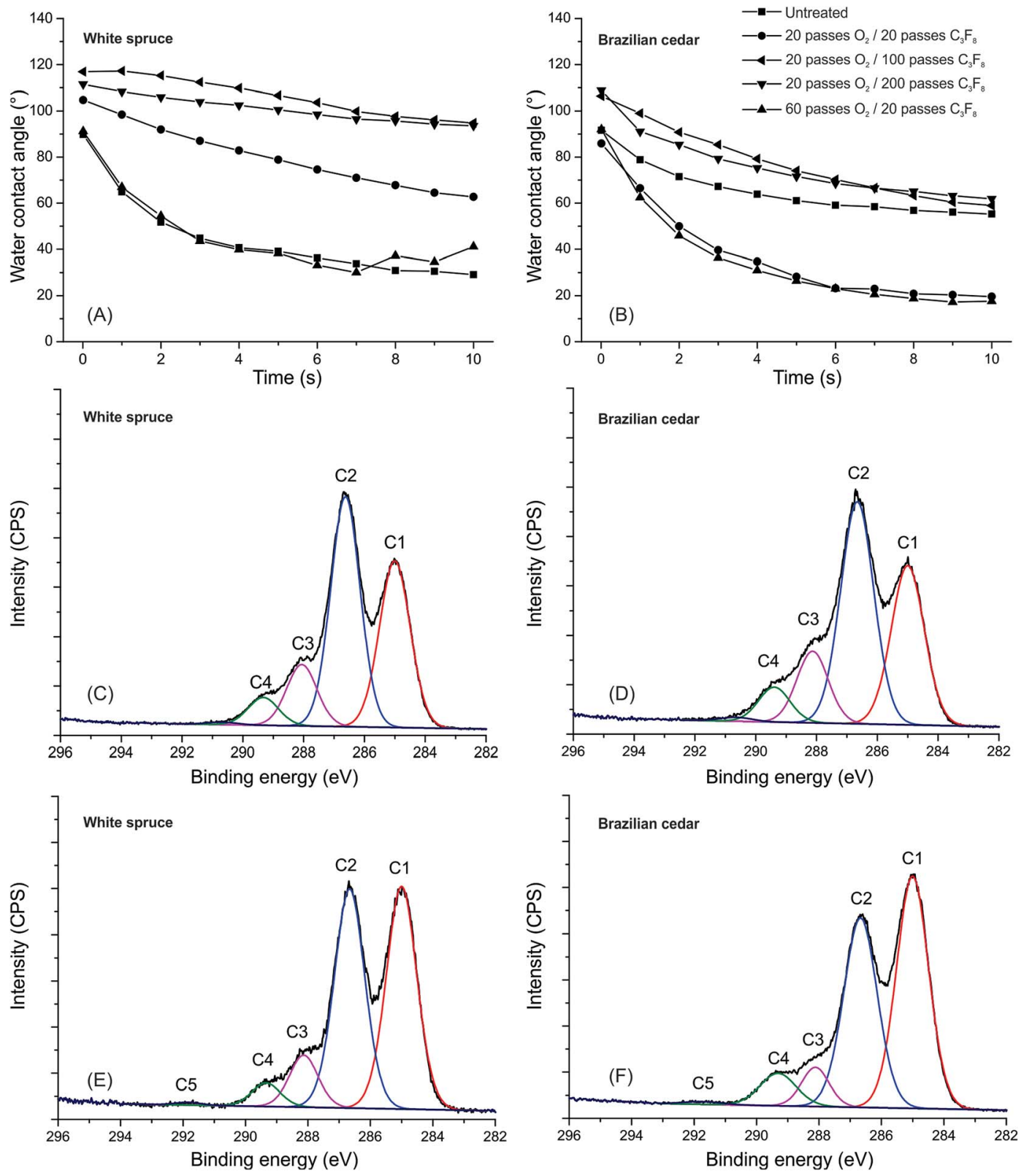

Fig. 5 Time-resolved water contact angle for the woods non-treated and treated by $\mathrm{Ar} / \mathrm{O}_{2}$ followed by a $\mathrm{Ar} / \mathrm{C}_{3} \mathrm{~F}_{8} \mathrm{DBD}$ afterglow plasma (A and B); high-resolution $C$ 1s spectra for the woods treated by $\mathrm{Ar} / \mathrm{O}_{2}$ with 60 passes (C and D); and treated by $\mathrm{Ar} / \mathrm{O}_{2}$ with 20 passes followed by a Ar/ $\mathrm{C}_{3} \mathrm{~F}_{8}$ with 20 passes ( $\mathrm{E}$ and $\mathrm{F}$ ) DBD afterglow plasma. 
than in $\mathrm{C}_{3} \mathrm{~F}_{8}$ deposition (20 passes) resulted in similar or higher wettability to the untreated wood surface, which reinforces the significant effect of the attachment of oxygen molecules on the surface.

This suggests that the chemical attachment of oxygen molecules is more significant than the physical changes made by the $\mathrm{O}_{2}$ plasma etching on the wood surface. The average values of Spk, Sk and Svk indicate an increase in the surface roughness of both woods due to the physical etching, mainly with 60 passes $\mathrm{O}_{2}$ (Fig. 6 and Table 4). The Sk increased by $33 \%$ and $47 \%$ in Brazilian cedar and white spruce wood, respectively. These parameters are based on the Abbot-curve and are utilized to separate the processing roughness data from the natural surface irregularities, ${ }^{52} \mathrm{such}$ as wood anatomical structures. For example, deep valleys are associated with the pores of the wood structure and should be removed before determining the wood roughness. ${ }^{53}$ Subsequently, this type of filter yields better conditions to show the specific changes made by the plasma treatments in this study and avoids misinterpretations. The attachment of oxygen molecules can be observed through the increase in the peaks related to oxygen-containing groups after the $\mathrm{O}_{2}$ plasma treatment (Fig. $5 \mathrm{C}$ and $\mathrm{D}$ ) and after the $\mathrm{O}_{2} / \mathrm{C}_{3} \mathrm{~F}_{8}$ plasma deposition (Fig. 5E and F). The most pronounced modification in both high-resolution $\mathrm{C}$ 1s spectra was the increment of $\mathrm{C}-\mathrm{O}$ groups ( $\mathrm{C} 2$ peak). According to Klarhöfer et al. ${ }^{54}$ oxygen plasma treatments lead to the oxidation of lignin and reduction of cellulose, which are the major chemical components of wood. This incorporation of oxygencontaining groups may be due to the formation of highly unstable free radicals on wood surfaces and their interaction with oxygen from the atmosphere during the atmospheric pressure plasma discharges. ${ }^{45}$

The addition of $\mathrm{O}_{2}$ in the gas phase during the plasma treatment at atmospheric pressure and the absence of direct contact between the substrate and the afterglow plasma discharge quench the formation of surface free radicals on the wood surface. ${ }^{36,45}$ Due to this, even with an increase in wood surface roughness, the attachment of oxygen molecules (as seen in the XPS patterns in Fig. 5) tends to decrease the quantity of chemically active sites available on the wood surface, which are mainly $\mathrm{C}-\mathrm{C}$ and $\mathrm{C}-\mathrm{H}$ groups, for the following fluorocarbon deposition. This leads to poor surface conditions for the fluorocarbon deposition, which results in easier interaction between the polar groups on the wood surface and water.

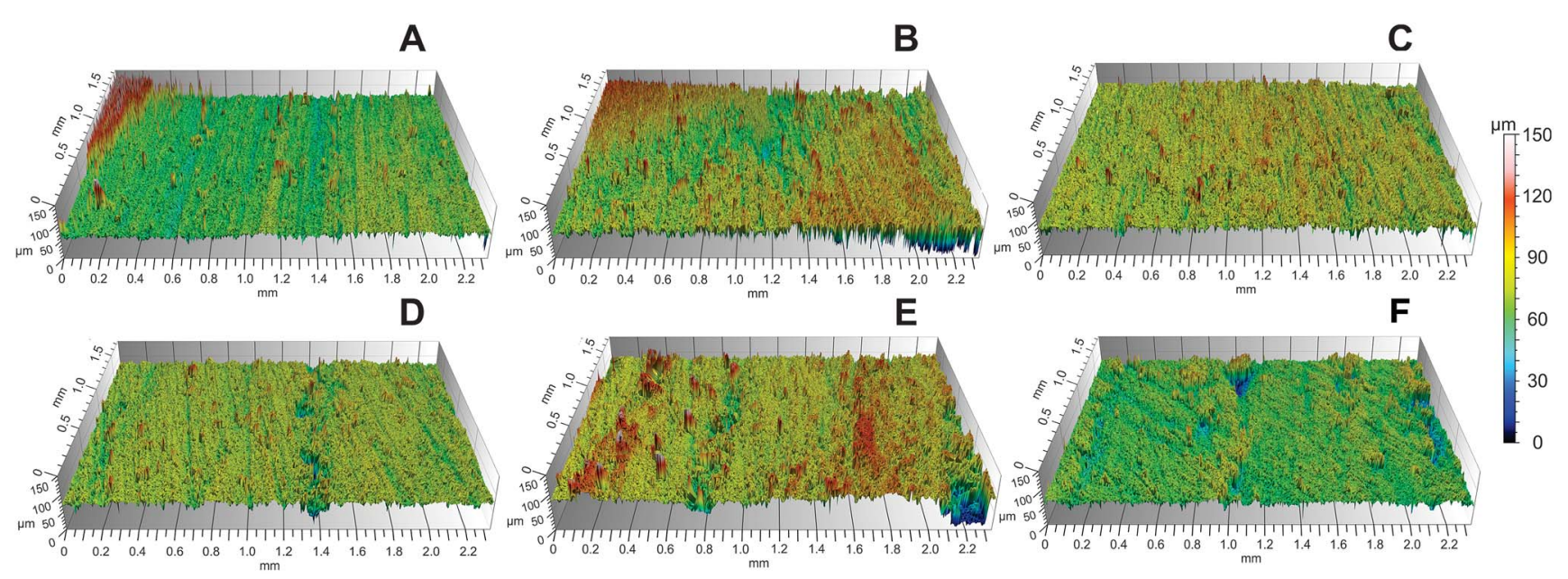

Fig. 6 Topographical images of wood non-treated ( $A$ and D), treated by $\mathrm{O}_{2}$ plasma with 60 passes ( $B$ and $E$ ) and treated by $C_{3} F_{8}$ plasma with 200 passes ( $C$ and F). Images at the top $=$ white spruce wood and images at the bottom $=$ Brazilian cedar wood.

Table 4 Surface roughness parameters of untreated and plasma treated white spruce and Brazilian cedar woods ${ }^{a}$

\begin{tabular}{|c|c|c|c|c|c|c|}
\hline \multirow[b]{2}{*}{ Plasma treatment } & \multicolumn{3}{|l|}{ White spruce } & \multicolumn{3}{|l|}{ Brazilian cedar } \\
\hline & Spk & Sk & Svk & Spk & Sk & Svk \\
\hline 20 passes $\mathrm{Ar}$ & $5.33(1.15) a b$ & $6.82(0.51) a b$ & $8.23(1.17) b c$ & $4.43(1.13) \mathrm{ab}$ & $5.27(0.43) \mathrm{a}$ & $6.36(0.58) \mathrm{ab}$ \\
\hline 20 passes $\mathrm{O}_{2}$ & $4.54(1.24) \mathrm{a}$ & $6.14(1.06) \mathrm{a}$ & $6.74(1.42) a b$ & $5.60(0.75) b c$ & $6.11(0.61) a b$ & $6.33(0.85) a b$ \\
\hline 60 passes $\mathrm{O}_{2}$ & $6.10(1.31) \mathrm{b}$ & $8.91(1.01) \mathrm{c}$ & $6.98(3.00) \mathrm{ab}$ & $6.79(1.23) \mathrm{c}$ & $6.85(0.59) \mathrm{b}$ & $6.79(1.52) \mathrm{b}$ \\
\hline
\end{tabular}

${ }^{a}$ Average values followed by the same letter in the column are not statistically different by the Tukey test $(p \geq 0.05)$. Values between parentheses correspond to the standard deviation. 
On the other hand, the fluorocarbon deposition by $\mathrm{Ar} / \mathrm{C}_{3} \mathrm{~F}_{8}$ plasma can change the surface roughness (Table 4). These changes are most evident in the white spruce wood. The Sk parameter increased by $23-27 \%$ after the $\mathrm{C}_{3} \mathrm{~F}_{8}$ deposition, which suggests that fluorine molecules can etch the wood surface at the same time that the fluorocarbon radicals form the hydrophobic film, as previously observed by Hubert et al. ${ }^{35}$ for $\mathrm{Ar}-$ $\mathrm{C}_{6} \mathrm{~F}_{14}$ plasma deposition at atmospheric pressure. In the case of the white spruce wood, the higher improvement in its roughness may partially explain its higher WCA after the $\mathrm{C}_{3} \mathrm{~F}_{8}$ deposition, regardless of the quantity of fluorocarbon radicals attached on its wood surface. Based on the negligent effect of ion bombardment at atmospheric pressure, Fanelli et al..$^{55}$ explained and proved this etching ability of fluoropolymers, which can be called depositionetching competition.

Considering the best treatments to enhance the water repellency of white spruce and Brazilian cedar woods, the aging effect was investigated (Fig. 7) after exposure in controlled conditions (temperature of $20{ }^{\circ} \mathrm{C}$ and $65 \%$ relative humidity).

After 40 days of exposure, the hydrophobic character of both wood species slightly changed (Fig. 7A and B). The wood species treated with 100 or 200 passes maintained a similar WCA in the range of $120-140^{\circ}$, which shows the low activity of the wood inactivation phenomenon. On the other hand, the exposure for 40 days resulted in a more hydrophobic surface for the wood treated with 20 passes, which is mainly due to the higher stability of the WCA with the time. This suggests that the insufficient fluorination in short treatments or the absence of fluorine-containing groups in the untreated wood favors the mechanisms of wood inactivation, thus leading to an increase in surface hydrophobicity. Among the many physical and chemical factors, this phenomenon of inactivation can occur due to the surface oxidation, modification of surface hydroxyl bonding sites and/or the migration of extractives on the wood surface. ${ }^{56}$ Free hydroxyl groups on the cell wall surfaces regulate the level of wettability and glueability of wood. The number of free hydroxyl groups tends to decrease during wood exposure mainly because the adsorption of polar molecules by the wood surface, such as water and volatile organic compounds, ${ }^{57}$ which results in a less reactive and a more hydrophobic surface. On the other hand, the migration of extractives to the wood surface is controversial in the literature, since a previous study confirmed the influence of this factor on the wettability and/or the reactivity of wood, ${ }^{58}$ whereas others stated the absence of a significant influence of extractives using wettability, extractive content, fracture and shear strength tests. ${ }^{59}$

As can be seen in Fig. 7C and D, the thin films deposited on the wood surface present partial defluorination, which occurs mainly because of environmental exposure. Nevertheless, this lower quantity of fluorine-containing groups could also be only in a specific point measured on the wood surface. Even with this partial defluorination, the wood surface of both species retained similar characteristics of water repellency. Therefore, unlike the untreated wood, it is believed that fluorocarbon films deposited on the wood surface may have good barrier properties to avoid or reduce the entire chemical reorganization of the
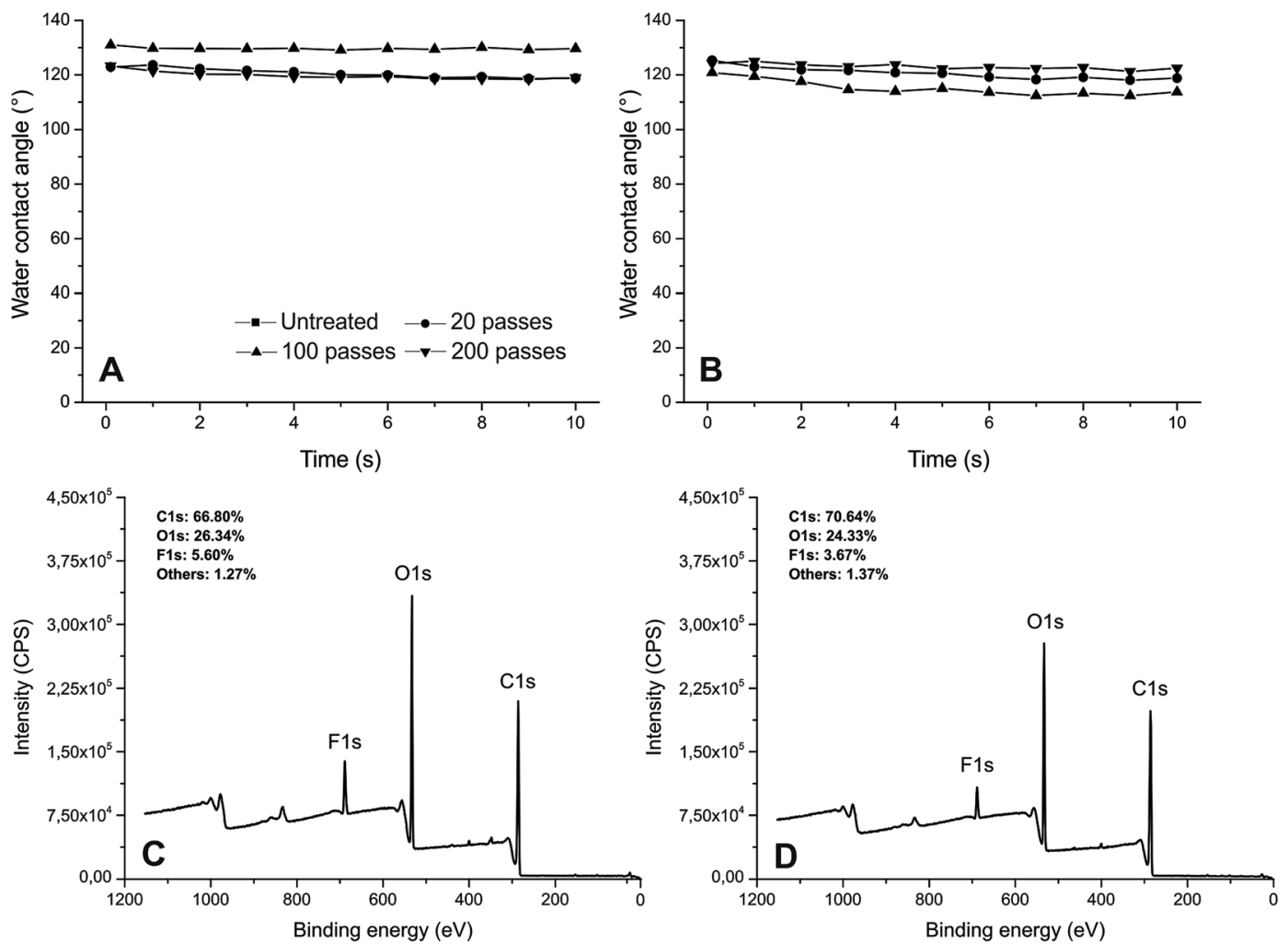

Fig. 7 Time-resolved water contact angle $\left(A\right.$ and $B$ ) and general survey spectra $(C$ and $D)$ for the woods untreated and treated with $A r / C_{3} F_{8} D B D$ afterglow plasma after exposure for 40 days in controlled conditions. 
surface during exposure in the environment, especially the potential migration of extractives and/or the accessibility of hydroxyl groups.

\section{Conclusions}

This study focused on obtaining a wood surface with higher water repellency via atmospheric pressure plasma deposition of fluorocarbon thin films, and investigated if a pre-treatment of $\mathrm{O}_{2}$ plasma can improve the water repellency of the wood-coated surface. A low surface energy layer was achieved on the wood surface by $\mathrm{C}_{3} \mathrm{~F}_{8}$ deposition in a DBD afterglow plasma system, which simulated an industrial line. Upon increasing the number of passes, the wood samples became more hydrophobic with a stable water contact angle, mainly for the white spruce. This better water repellency is due to the higher presence of $\mathrm{CF}$ functional groups on the surface. The addition of a pretreatment of $\mathrm{O}_{2}$ did not help to increase the degree of wood surface hydrophobicity since the attachment of oxygen molecules on the surface superimposes the physical changes made by the $\mathrm{O}_{2}$ plasma etching. The fluorocarbon deposition was better suited to increase the wood roughness for both white spruce and Brazilian cedar wood species, which caused the surfaces to be more hydrophobic due to the simultaneous etching and chemical deposition. Furthermore, the fluorocarbon deposition results in a wood surface resistant to aging, especially for longer treatments ( $>100$ passes). The most pronounced improvement in roughness in the white spruce wood was mandatory for a better degree of water repellency since both woods presented a similar quantity of fluorocarbon deposited on their surface.

\section{Acknowledgements}

The authors are grateful to the Conselho Nacional de Desenvolvimento Científico e Tecnológico (CNPq, process 202617) 2015-7), the Canadian International Scholarship Emerging Leaders in the Americas Program (ELAP) and the Natural Sciences and Engineering Research Council of Canada for the financial support through its IRC and CRD programs (IRCPJ 461745-12 and RDCPJ 445200-12) as well as the industrial partners of the NSERC industrial chair on eco-responsible wood construction (CIRCERB) and FPInnovations for access to the plasma reactor.

\section{References}

1 L. Gao, S. Xiao, W. Gan, X. Zhan and J. Li, RSC Adv., 2015, 5, 98203-98208.

2 A. Kumar, P. Ryparová, A. S. Škapin, M. Humar, M. Pavlič, J. Tywoniak, P. Hajek, J. Žigon and M. Petrič, Cellulose, 2016, 23, 3249-3263.

3 Z. Chu and S. Seeger, RSC Adv., 2015, 5, 21999-22004.

4 Z. Tang, L. Xie, D. W. Hess and V. Breedveld, Wood Sci. Technol., 2017, 51, 97-113.

5 A. Fridman, A. Chirokov and A. Gutsol, J. Phys. D: Appl. Phys., 2005, 38, R1.
6 P. Attri, B. Arora and E. H. Choi, RSC Adv., 2013, 3, 1254012567.

7 R. Morent, N. De Geyter, J. Verschuren, K. De Clerck, P. Kiekens and C. Leys, Surf. Coat. Technol., 2008, 202, 3427-3449.

8 S. Zanini, C. Riccardi, M. Orlandi, V. Fornara, M. Colombini, D. Donato, S. Legnaioli and V. Palleschi, Wood Sci. Technol., 2008, 42, 149-160.

9 R. Shishoo, Plasma technologies for textiles, CRC Press LLC, USA, 2007.

10 M. J. Perez-Roldan, D. Debarnot and F. Poncin-Epaillard, RSC Adv., 2014, 4, 64006-64013.

11 S.-C. Jung, K. Lee and B.-H. Kim, Thin Solid Films, 2012, 521, 150-154.

12 H.-R. Jiang and D.-C. Chan, Appl. Phys. Lett., 2016, 108, 171603.

13 M. R. Chashmejahanbin, A. Salimi and A. Ershad Langroudi, Int. J. Adhes. Adhes., 2014, 49, 44-50.

14 H. Peng, G. Zheng, Y. Sun and R. Wang, RSC Adv., 2015, 5, $78172-78179$.

15 N. Tenn, N. Follain, K. Fatyeyeva, F. Poncin-Epaillard, C. Labrugere and S. Marais, RSC Adv., 2014, 4, 5626-5637.

16 Y. de Rancourt, B. Couturaud, A. Mas and J. J. Robin, J. Colloid Interface Sci., 2013, 402, 320-326.

17 P. H. G. Cademartori, G. I. B. Muniz and W. L. E. Magalhães, Holzforschung, 2015, 69, 187.

18 B. Hünnekens, F. Peters, G. Avramidis, A. Krause, H. Militz and W. Viöl, J. Appl. Polym. Sci., 2016, 133, 43376.

19 I. Novák, A. Popelka, Z. Špitalský, M. Mičušík, M. Omastová, M. Valentin, J. Sedliačik, I. Janigová, A. Kleinová and M. Šlouf, Vacuum, 2015, 119, 88-94.

20 P. Král, J. Ráhel', M. Stupavská, J. Šrajer, P. Klímek, P. Mishra and R. Wimmer, Wood Sci. Technol., 2015, 49, 319-330.

21 D. Altgen, M. Bellmann, R. Wascher, W. VioL and C. Mai, Eur. J. Wood Wood Prod., 2015, 73, 219-223.

22 L. Xie, Z. Tang, L. Jiang, V. Breedveld and D. W. Hess, Surf. Coat. Technol., 2015, 281, 125-132.

23 B. Poaty, B. Riedl, P. Blanchet, V. Blanchard and L. Stafford, Wood Sci. Technol., 2013, 47, 411-422.

24 H. T. Sahin, Appl. Surf. Sci., 2013, 265, 564-569.

25 W. L. E. Magalhães and M. F. d. Souza, Surf. Coat. Technol., 2002, 155, 11-15.

26 A. R. Denes, M. A. Tshabalala, R. Rowell, F. Denes and R. A. Young, Holzforschung, 1999, 53, 318-326.

27 F. Fanelli and F. Fracassi, Plasma Chem. Plasma Process., 2014, 34, 473-487.

28 O. Levasseur, L. Stafford, N. Gherardi, N. Naudé, E. Beche, J. Esvan, P. Blanchet, B. Riedl and A. Sarkissian, Surf. Coat. Technol., 2013, 234, 42-47.

29 O. Levasseur, L. Stafford, N. Gherardi, N. Naudé, V. Blanchard, P. Blanchet, B. Riedl and A. Sarkissian, Plasma Processes Polym., 2012, 9, 1168-1175.

30 G. Avramidis, E. Hauswald, A. Lyapin, H. Militz, W. Viöl and A. Wolkenhauer, Wood Mater. Sci. Eng., 2009, 4, 52-60.

31 J. Profili, O. Levasseur, A. Koronai, L. Stafford and N. Gherardi, Surf. Coat. Technol., 2017, 309, 729-737. 
32 M. Bente, G. Avramidis, S. Förster, E. G. Rohwer and W. Viöl, Holz Roh-Werkst., 2004, 62, 157-163.

33 G. Toriz, M. G. Gutiérrez, V. González-Alvarez, A. Wendel, P. Gatenholm and A. d. J. Martínez-Gómez, J. Adhes. Sci. Technol., 2008, 22, 2059-2078.

34 F. Busnel, V. Blanchard, J. Prégent, L. Stafford, B. Riedl, P. Blanchet and A. Sarkissian, J. Adhes. Sci. Technol., 2010, 24, 1401-1413.

35 J. Hubert, N. Vandencasteele, J. Mertens, P. Viville, T. Dufour, C. Barroo, T. Visart de Bocarmé, R. Lazzaroni and F. Reniers, Plasma Processes Polym., 2015, 12, 1174-1185.

36 J. Prégent, L. Vandsburger, V. Blanchard, P. Blanchet, B. Riedl, A. Sarkissian and L. Stafford, Cellulose, 2015, 22, 3397-3408.

37 L. Tang, R. Zhang, X. Zhou, M. Pan, M. Chen, X. Yang, P. Zhou and Z. Chen, BioResources, 2012, 7, 3327-3339.

38 M. N. Acda, E. E. Devera, R. J. Cabangon and H. J. Ramos, Int. J. Adhes. Adhes., 2012, 32, 70-75.

39 L. Tang, R. Zhang, X. Wang, X. Yang and X. Zhou, Journal, 2015, 69, 193.

40 B. Riedl, C. Angel, J. Prégent, P. Blanchet and L. Stafford, BioResources, 2014, 9, 4908-4923.

41 S. Wu, J. Polym. Sci., Part C: Polym. Symp., 1971, 34, 19-30.

42 S. Wu, J. Adhes., 1973, 5, 39-55.

43 K. K. Samanta, A. G. Joshi, M. Jassal and A. K. Agrawal, Surf. Coat. Technol., 2012, 213, 65-76.

44 M. Moreno-Couranjou, N. D. Boscher, D. Duday, R. Maurau, E. Lecoq and P. Choquet, in Atmospheric Pressure Plasma Treatment of Polymers: Relevance to Adhesion, ed. M. Thomas and K. L. Mittal, Wiley-Scrivener, 2013, vol. 1.
45 J.-M. Hardy, O. Levasseur, M. Vlad, L. Stafford and B. Riedl, Appl. Surf. Sci., 2015, 359, 137-142.

46 S. R. Coulson, I. S. Woodward, J. P. S. Badyal, S. A. Brewer and C. Willis, Chem. Mater., 2000, 12, 2031-2038.

47 A. Quade, K. Schröder, A. Ohl and K.-D. Weltmann, Plasma Processes Polym., 2011, 8, 1165-1173.

48 Z. Liu, P. Chen, X. Zhang, Q. Yu, K. Ma and Z. Ding, Appl. Surf. Sci., 2013, 283, 38-45.

49 D. Liu, P. Chen, J. Mu, Q. Yu and C. Lu, Appl. Surf. Sci., 2011, 257, 6935-6940.

50 M. N. Mirvakili, S. G. Hatzikiriakos and P. Englezos, ACS Appl. Mater. Interfaces, 2013, 5, 9057-9066.

51 L. Li, V. Breedveld and D. W. Hess, ACS Appl. Mater. Interfaces, 2013, 5, 5381-5386.

52 L. Gurau, Doctoral thesis, Brunel University, 2004.

53 Y. Fujiwara, Y. Fujii, Y. Sawada and S. Okumura, J. Wood Sci., 2004, 50, 35-40.

54 L. Klarhöfer, W. Viöl and W. Maus-Friedrichs, Journal, 2010, 64, 331.

55 F. Fanelli, F. Fracassi and R. D'Agostino, Surf. Coat. Technol., 2010, 204, 1779-1784.

56 A. W. Christiansen, Wood Fiber Sci., 1991, 23, 69-84.

57 C. Piao, J. E. Winandy and T. F. Shupe, Wood Fiber Sci., 2010, 42, 490-510.

58 P. Nzokou and D. P. Kamdem, Wood Fiber Sci., 2004, 36, 483492.

59 R. M. Nussbaum and M. Sterley, Wood Fiber Sci., 2002, 34, 57-71. 